\title{
Resection margins do not influence survival in vulvar cancer: treatment results in patients with a long-term follow-up
}

\author{
Szymon Piątek', Wojciech Michalski², Mariusz Bidziński', Anna Dańska-Bidzińska³ \\ 'Department of Gynecologic Oncology, Maria Sklodowska-Curie National Research Institute of Oncology, Warsaw, Poland \\ ${ }^{2}$ Department of Biostatics, Maria Skłodowska-Curie National Research Institute of Oncology, Warsaw, Poland \\ ${ }^{3} 2^{\text {nd }}$ Chair and Department Obstetrics and Gynecology, Medical University of Warsaw, Warsaw, Poland
}

Introduction. The main purpose of the study was to assess margin resection as a prognostic factor of vulvar cancer in patients with a long term follow-up.

Materials and methods. The study included 84 vulvar cancer patients who underwent radical treatment: surgery $(n=84)$, radiotherapy $(n=16)$, chemoradiotherapy $(n=5)$. Clinicopathological factors regarding survival and recurrence were analyzed. The median follow-up was 74 months.

Results. Resection margins were not related to progression-free survival (PFS) ( $p=0.93)$ and overall survival (OS) ( $p=0.84)$. On the multivariate analysis, a maximum tumor size $>25 \mathrm{~mm}(p=0.026)$ and inguinal lymph node involvement $(p=0.028)$ were factors increasing the risk of death. The risk of recurrence was related to tumor dimension $>25 \mathrm{~mm}$ ( $p=0.011$ ), but not to inguinal node metastasis $(p=0.086)$.

Discussion. Inadequate surgical margin would be salvaged by adjuvant treatment.

Conclusions. A maximum tumor dimension $>25 \mathrm{~mm}$ and metastases in the inguinal lymph nodes are independent prognostic factors for the survival of patients with vulvar cancer.

Key words: vulva, cancer, prognosis, recurrence

\section{Introduction}

Inguinal lymph node involvement is unquestionably a prognostic factor in vulvar cancer. It is believed that resection margins are also of great importance in the management of vulvar cancer. Subsequently, the main goal of surgical treatment is to achieve a wide margin (according to NCCN: $1-2 \mathrm{~cm}$, ESGO - $8 \mathrm{~mm}$ ) [1, 2]. Recently, some studies question the importance of a wide excision and show no correlation between margin width and recurrence $[3,4]$.

Follow-up is recommended in all patients for $4-5$ years after treatment [1,2]; conducting longer observations is difficult due to the advanced age of patients at diagnosis, limitations of healthcare, rare incidence and the dispersal of patients.

The main purpose of the study was to assess margin resections as a prognostic factor of vulvar cancer in long term follow-up. An additional aim was to identify clinicopathological and treatment related-factors (other than margin) influencing survival and affecting treatment failures in vulvar cancer patients in long term follow-up scenarios.

\section{Material and methods}

The retrospective analysis included 84 patients with vulvar cancer treated at Maria Sklodowska-Curie National Research

\section{How to cite:}

Piątek S, Michalski W, Bidziński M, Dańska-Bidzińska A. Resection margins do not influence survival in vulvar cancer: treatment results in patients with a long-term follow-up. NOWOTWORY J Oncol 2021; 71: 290-295. 
Institute of Oncology between 2001 and 2007. Women with contraindications to surgical treatment due to advanced disease and severe comorbidities were not included. The stage of the disease was evaluated according to the 1994 FIGO classification, which was valid at the time. For this study, staging was reclassified to the 2009 FIGO. All patients were diagnosed with vulvar squamous cell carcinoma and underwent a radical vulvectomy with inguinal lymphadenectomy. 31 patients required adjuvant treatment according to the following criteria:

- resection margin $\leq 1 \mathrm{~mm}$ or positive,

- metastasis to $\geq 1$ inguinal lymph node.

Ten patients did not undergo adjuvant therapy due to comorbidities and poor general condition $(n=3)$, lack of consent to radiotherapy $(n=2)$, abnormal wound healing ( $n=2)$, skipping appointments $(n=1)$, the patient's death $(n=1)$, unknown reasons $(n=1) .21$ patients were treated with radiotherapy $(R T, n=16)$ and radiochemotherapy $(R C T, n=5)$.

Adjuvant external beam radiation therapy (EBRT) with linear accelerator and energy of 4-15 MeV was applied to the vulva $(n=6)$, vulva and groins $(n=5)$, groins $(n=5)$ and pelvic region $(n=5)$. A total dose of $4800-6000$ cGy was administered in 24-31 fractions. In 5 patients, concomitant cisplatin intravenously was administered intravenously with a dose of $40 \mathrm{mg} / \mathrm{m}^{2}$, once a week. The duration of RT and RCT was 31-43 and 38-48 days, respectively. Adjuvant treatment started within 6 weeks of surgery.

Follow-up: gynecological examination, transvaginal and inguinal ultrasonography were conducted every 3-4 months for 2 years, then every 6 months for the next 3 years. A chest $X$-ray was carried out once a year. Computed tomography or magnetic resonance were performed in patients with suspicion of relapse. After 5 years, patients continued follow-up once a year in our outpatient clinic or outpatient clinic near their place of residence. Information was obtained by telephone for those patients who carried out a gynecological follow-up outside our center, Data on death were collected from the National Cancer Registry.

Recurrence: a biopsy of the suspicious lesion was performed to obtain a histopathological confirmation; the date of the positive biopsy was considered as the moment of relapse. Locoregional recurrence was defined as relapse in the vulva and/or groins. Distant metastases were not observed in the study group. Treatment of relapse disease was presented in table I.

Age, tumor grade, staging, maximum tumor dimension, depth of stromal invasion, status of inguinal lymph nodes, and the number of metastatic lymph nodes were considered as clinicopathological factors, while margin, number of resected lymph node and lymph node ratio were treatment-related factors.

\section{Methods of statistical analysis}

Efficacy of treatment was measured by the probability of survival - overall survival (OS), progression-free survival (PFS) and cumulative incidence function (CIF) of local relapses. Survival curves were calculated using the Kaplan-Meier method. Overall survival was estimated from the date of treatment initiation to death or the last information provided when the patient was alive. Progression-free survival was measured from the date of treatment initiation to its first failure: local relapse, distant metastases or death from other causes; in the absence of treatment failure, PFS was estimated to the last clinical observation. To evaluate the influence of selected factors such as age, grading, staging, tumor size, lymph node metastases, depth of invasion, margins, total number of lymph nodes removed, and the number of metastatic lymph nodes on OS and PFS, the Cox proportional hazard model was used. The influence of these factors on the risk of recurrence was analyzed using a multivariate model for competitive risks. The modeling process used a step-by-step elimination of variables by adopting standard thresholds: off (>0.1) and on (<0.05). The analysis was carried out using the IBM SPSS Statistics 23.0 statistical package and the Bob Gray package [6].

\section{Ethics approval}

All procedures were conducted according to the Declaration of Helsinki for Medical Research involving Human Subjects. Institutional ethics committee approval was not required - the research is an ex-post analysis of clinical experience. The clinical decisions concerning the treatment were not influenced by the purpose of this paper.

Table I. Treatment of recurrence of vulvar cancer depending on location

\begin{tabular}{|lccc|}
\hline Treatment & \multicolumn{2}{c|}{ Location of relapse } \\
\hline & vulva $(\mathbf{n}=23)$ & groin $(\mathbf{n = 1 2})$ & vulva and groin $(\mathrm{n}=2)$ \\
\hline surgery & 10 & 3 & 0 \\
\hline radiotherapy & 3 & 3 & 0 \\
\hline chemotherapy & 5 & 0 & 0 \\
\hline radiochemotherapy & 2 & 0 & 0 \\
\hline brachyterapy & 3 & 5 & 2 \\
\hline palliative & 2 & 1 & 0 \\
\hline
\end{tabular}


Table II. Clinicopathological characteristics of study group

\begin{tabular}{|c|c|c|}
\hline Factor & & n (\%) \\
\hline \multirow[t]{3}{*}{ age (years) } & $<62$ & $26(31 \%)$ \\
\hline & $62-73$ & $30(35.7 \%)$ \\
\hline & $\geq 74$ & $28(33.3 \%)$ \\
\hline \multirow[t]{2}{*}{ lymphadenectomy } & & $10(11.9 \%)$ \\
\hline & bilateral & $74(88.1 \%)$ \\
\hline median resected lymph nodes & & $11(3-28)$ \\
\hline \multirow[t]{5}{*}{ FIGO 1994/2009 } & $\mathrm{IA}$ & $1(1.2 \%) / 1(1.2 \%)$ \\
\hline & $\mathrm{IB}$ & $11(13.1 \%) / 46(54.8 \%)$ \\
\hline & $\|$ & $35(41.7 \%) / 12(14.3 \%)$ \\
\hline & III & $31(36.9 \%) / 21(25 \%)$ \\
\hline & IV & $6(7.14 \%) / 4(4.7 \%)$ \\
\hline \multirow[t]{4}{*}{ grading } & 1 & $29(34.5 \%)$ \\
\hline & 2 & $37(44 \%)$ \\
\hline & 3 & $12(14.3 \%)$ \\
\hline & unknown & $6(7.14 \%)$ \\
\hline \multirow{4}{*}{$\begin{array}{l}\text { maximum tumor diameter } \\
(\mathrm{mm})\end{array}$} & $\leq 25$ & $31(36.9 \%)$ \\
\hline & $26-44$ & $22(26.2 \%)$ \\
\hline & $\geq 45$ & $30(35.7 \%)$ \\
\hline & unknown & $1(1.2 \%)$ \\
\hline \multirow[t]{2}{*}{ multifocal lesion } & no & $79(94 \%)$ \\
\hline & yes & $5(6 \%)$ \\
\hline \multirow[t]{3}{*}{ depth of invasion (mm) } & $\leq 5$ & $28(33.33 \%)$ \\
\hline & $>5$ & $40(47.62 \%)$ \\
\hline & unknown & $16(19.05 \%)$ \\
\hline \multirow[t]{5}{*}{ margin (mm) } & positive & $5(5.95 \%)$ \\
\hline & $\leq 1$ & $15(17.86 \%)$ \\
\hline & $>1-5$ & $30(35.71 \%)$ \\
\hline & $>5$ & $30(35.71 \%)$ \\
\hline & $\begin{array}{l}\text { negative (not } \\
\text { measured) }\end{array}$ & $4(4.76 \%)$ \\
\hline
\end{tabular}

\section{Results}

The clinicopathological characteristics of the study group ( $n=84$ ) was shown in table ll. Patients'average age was 66 years (18-94). The median tumor size was $35 \mathrm{~mm}$ (5-90 mm). Microinvasion (depth of stromal invasion $<1 \mathrm{~mm}$ ) was found in 1 patient (1.2\%). Median number of resected lymph nodes per groin was 6 (1-15). In 26 (30.95\%) patients, metastases to the inguinal lymph nodes were found; 13 (17.86\%) patients had involved $>1$ inguinal lymph node ( 2 metastatic LNs in 4 patients, 3 metastatic LNs in 3 patients, 5 metastatic LN in 3 patients, 8 metastatic LNs in 2 patients and 9 metastatic LNs in 1 patient).

\section{Survival}

The median overall survival (OS) and progression free survival (PFS) was 87 (95\% Cl: 60-114) and 60 (95\% Cl: 37-84) months, respectively. The overall 5- and 10-year survival rates were 62\% (95\% Cl: 51-73\%) and 39\% (95\%Cl: 28-50\%), while 5- and 10-year PFS were 51\% (95\% Cl: 40-62\%) and 32\% (95\% Cl: 22-42\%), respectively.
On the multivariate analysis, the resection margin was not related to PFS (HR $=1.033 ; 95 \% \mathrm{Cl}: 0.51-2.11 ; \mathrm{p}=0.93)$ and $\mathrm{OS}$ $(H R=0.84 ; 95 \% \mathrm{Cl}: 0.41-1.73 ; \mathrm{p}=0.84)$.

On the multivariate analysis, factors influencing survival were: maximum tumor size and inguinal lymph node status (fig. 1, tab. III). Other clinicopathological and treatment- related factors did not have a significant effect on survival.

Maximum tumor size was the only factor influencing PFS on multivariate analysis; nor inguinal lymph node involvement or other analyzed factors were not relevant to PFS (fig. 2, tab. III).

\section{Failure patterns}

The majority of relapses occurred within 2 years from the end of treatment and were localized on the vulva and groins. Cumulative incidence function (CIF) curves according to the site of relapse as competing risk had similar patterns for 2 years (fig. 3). At 15 years, CIF by site of relapse and non-cancer death as competing risk were: vulva $28 \%$ (95\% Cl: $18-38 \%)$, groin 17\% (95\% Cl: 8.7-25\%) and non-cancer death 27\% (95\% Cl: 18-37\%). Late recurrences ( $>5$ years after the end of the treatment) affected the vulva.

Occurrence of locoregional relapse (vulva and/or groins) was significantly dependent on the maximum tumor size ( $p=0.019)$. In the final model, the HR was 2.37 (95\% Cl: 1.15-4.89) for tumors $>25 \mathrm{~mm}$ vs. $\leq 25 \mathrm{~mm}$. The CIF curves are presented in figure 4. Other clinicopathological and treatmentrelated factors (including resection margin) did not have an influence on the risk of relapse.

\section{Survival after recurrence}

Groin recurrence influenced OS significantly ( $p<0.007)$. The median survival after relapse in patients with groin recurrence vs vulva recurrence was 6.1 (95\% Cl: 2.7-9.5) vs. 16 (95\% Cl: 8.7-23.5) months, respectively.

\section{Discussion}

The principles of surgical treatment of vulvar cancer are inguinal lymph node assessment and wide margin excision. It was showed that margins $\geq 5 \mathrm{~mm}$ or $\geq 8 \mathrm{~mm}$ were significantly associated with risk of recurrence and survival [5-7]. In our study, the margin did not influence survival and recurrence. However, some patients with a close resection margin received adjuvant radiotherapy, which could affect the results. Similar results to ours were obtained in other studies [8-10]. Arvas et al. showed that a margin $\leq 2 \mathrm{~mm}$ may increase the risk of recurrence, but was not an independent predictive factor for PFS and OS [11]. Woelber et al. showed a similar rate of local recurrence in patients with a margin $<8 \mathrm{~mm}$ vs. $\geq 8 \mathrm{~mm}(12.6 \%$ vs. $10.2 \%$ respectively) [12]. German recommendations accept a margin of $3 \mathrm{~mm}$ as sufficient [13]. Several authors claim that a positive margin is the only risk factor for recurrence; a complete resection with no lower limit (besides positive margin) should be recommended [14-16]. 

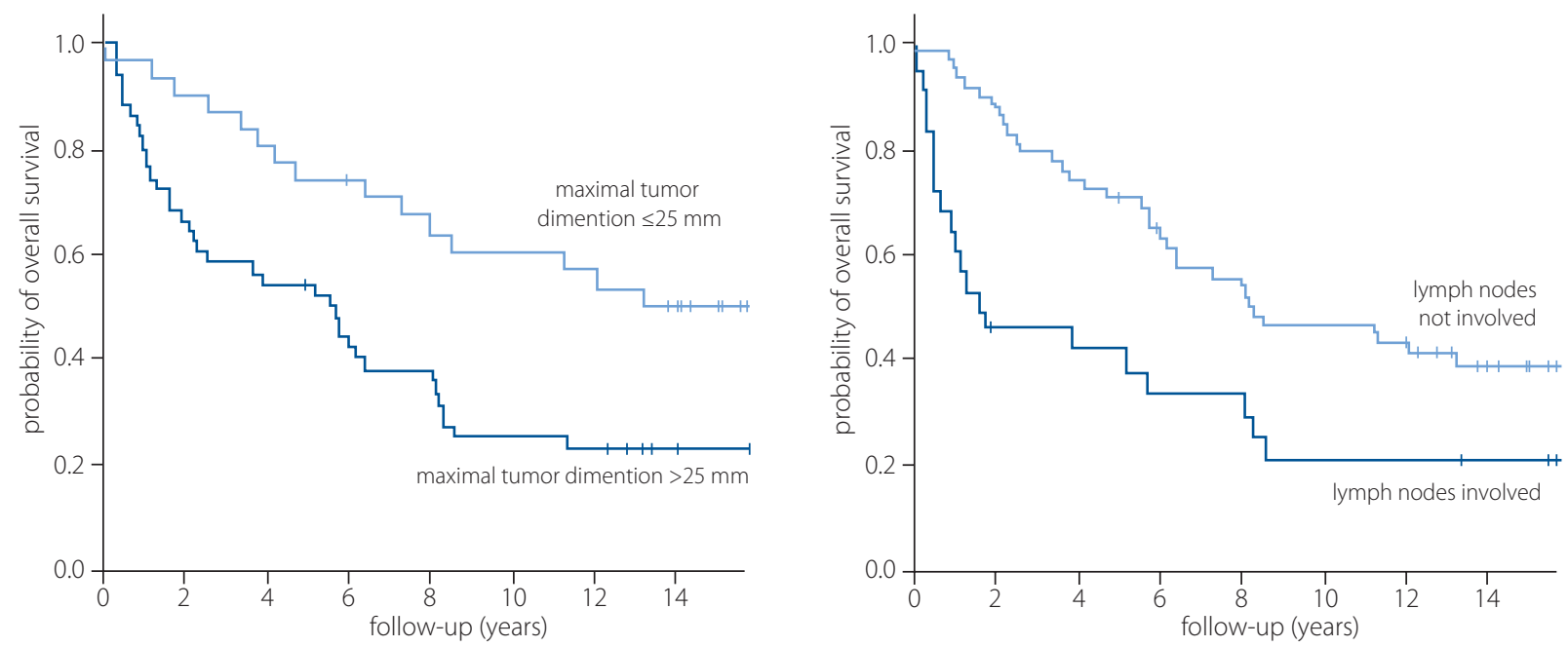

Figure 1. Overall survival by tumor dimension $(p=0.026)$ and status of inguinal lymph nodes $(p=0.028)$

Table III. Multivariate analysis of clinicopathological factors affecting overall survival

\begin{tabular}{|c|c|c|c|c|c|}
\hline Endpoint & Factor & & $\mathrm{HR}$ & $95 \% \mathrm{Cl}$ & p \\
\hline \multirow[t]{4}{*}{ overall survival } & maximum tumor dimension & $\leq 25 \mathrm{~mm}$ & 1 & & \\
\hline & & $>25 \mathrm{~mm}$ & 2.038 & $1.091-3.808$ & 0.026 \\
\hline & groin lymph nodes metastasis & no & 1 & & \\
\hline & & yes & 1.903 & $1.074-3.372$ & 0.028 \\
\hline \multirow[t]{4}{*}{ progression free survival } & maximum tumor dimension & $\leq 25 \mathrm{~mm}$ & 1 & & \\
\hline & & $>25 \mathrm{~mm}$ & 2.208 & $1.203-4.055$ & 0.011 \\
\hline & groin lymph node metastasis & no & 1 & & \\
\hline & & yes & 1.625 & $0.933-2.830$ & 0.086 \\
\hline
\end{tabular}
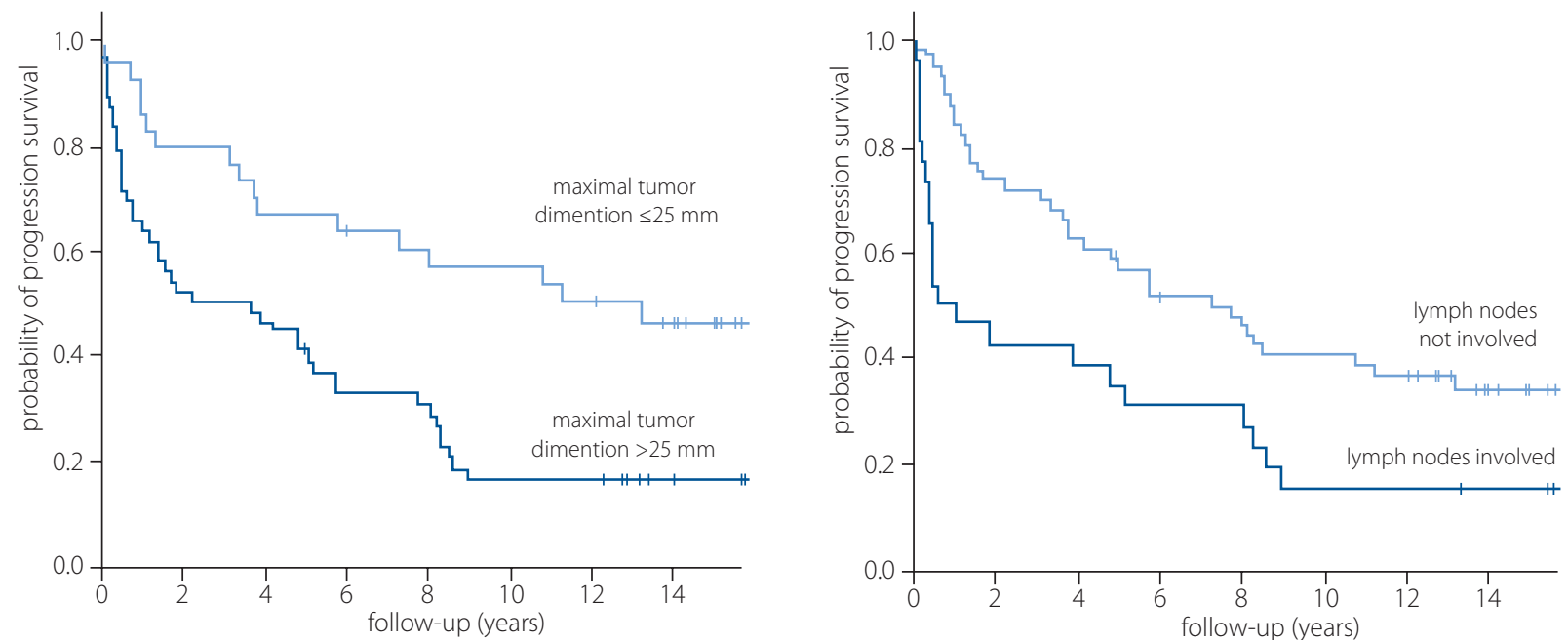

Figure 2. Progression free survival by maximum tumor size $(p=0.011)$ and status of inguinal lymph nodes $(p=0.086)$

Long-term observation showed that a tumor size $>25 \mathrm{~mm}$ and metastases to regional lymph nodes increased the risk of death in patients with vulvar cancer. Inguinal lymph node involvement has been directly related to shorter survival, while maximum tumor size negatively influenced survival by increas- ing the risk of recurrence. The results of other authors also indicate that the tumor size and the involvement of regional lymph nodes influence survival. Minar et al. showed that a tumor dimension $>40 \mathrm{~mm}$ and metastases in inguinal lymph nodes are significantly associated with a risk of recurrence [17]. 


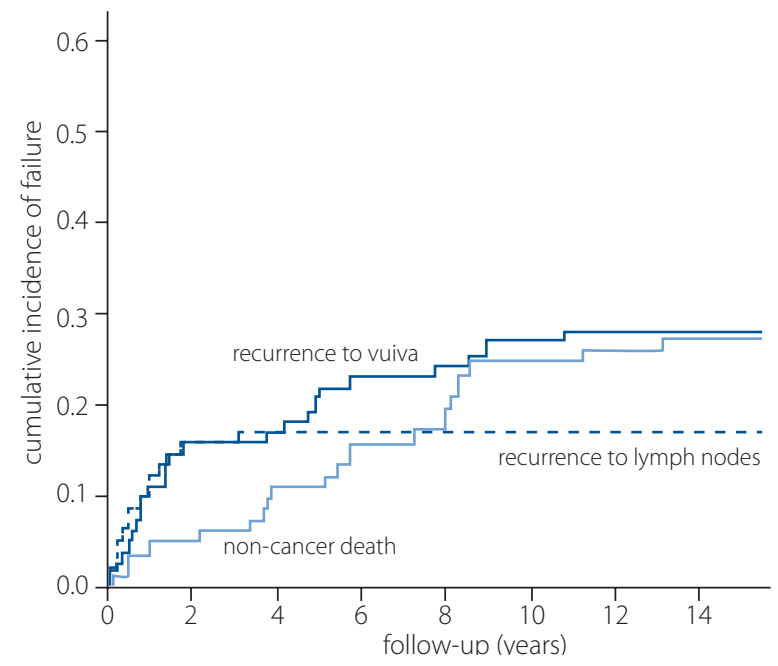

Figure 3. Cumulative incidence function (CIF) curves by site of recurrence and non-cancer death as competing risk

Hay et al. found that tumors $>4 \mathrm{~cm}$ increased disease-specific mortality 4-fold, but were not related to relapse [18]. Imoto et al., on multivariate analysis, showed that inguinal lymph node involvement influenced PFS, but not OS [5].

The extracapsular spread of lymph nodes was found to be an independent prognostic factor for recurrence (HR 13.54; 95\% Cl: 2.87-64.07; $p=0.01$ ) and overall survival (HR 10.63; $95 \%$ Cl: 1.65-68.57; $p=0.01$ ) [19]. An increasing number of metastatic lymph nodes was associated with a risk of recurrence and death $[20,21]$. In our study, there was no relationship between the number of metastatic lymph nodes and survival, probably due to the insufficient number of patients.

Our results, showing that tumor grade did not influence recurrence risk and survival, were consistent with other studies $[8,19,21-24]$. Although Nicoletto et al. on univariate analysis showed that grading was associated with PFS and OS (5-year survival $52 \%$ for grade $1 ; 24 \%$ for grade 2 vs. $0 \%$ for grade 3 , $p=0.0021$ ); these findings were not confirmed on multivariate analysis [25]. Mahner et al. and Polterauer et al. demonstrated that tumor grade is predictive for PFS, but not for OS [21, 26]. Multivariable analysis by Sznurkowski et al. revealed that grading was an independent prognostic factor [27].

The depth of stromal infiltration is crucial to confirm microinvasion ( $\leq 1 \mathrm{~mm}$; FIGO IA). In these cases, verification of inguinal lymph nodes may be omitted due to the minimal risk of metastases. The depth of infiltration in invasive disease does not influence therapeutic decisions and its impact on survival is doubtful. We did not find a relationship between the depth of invasion and the risk of relapse in the primary site, PFS and OS length. Similar results were obtained by other authors [19, 21, $23,27,28]$. Contrary to this, Nicoletto et al. demonstrated that stromal invasion $>9 \mathrm{~mm}$ was an important prognostic factor for PFS (HR $=3.1 ; 95 \% \mathrm{Cl}: 1.3-7.7)$ (25). While in the VULCAN study, stromal invasion $>5 \mathrm{~mm}$ appeared to significantly impact overall survival [29].

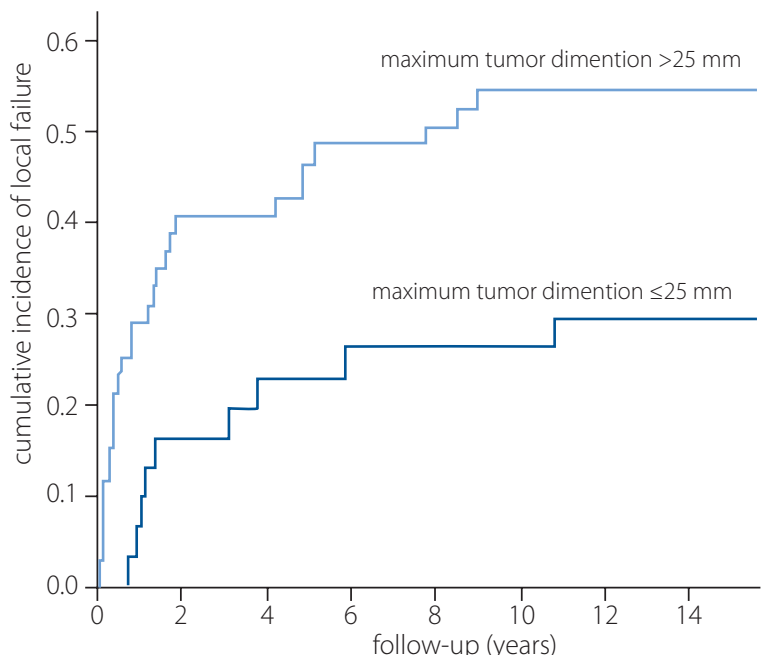

Figure 4. Cumulative incidence function (CIF) of locoregional relapse depending on the size of the tumor

The results of our study indicate the need for long-term observation of vulvar cancer patients. Relapses of the disease can occur years after the end of the treatment (fig. 4). In our study group, all cases of late recurrence were located in the vulva. Many patients after the standard 5-year follow-up continue healthcare beside oncology unit/outpatient clinic. General practitioners or obstetricians/gynecologists as well as patients should be informed about the possibility of late relapse and its most frequent location.

The site of locoregional relapse influenced survival. Groin recurrence was associated with a much poorer prognosis than vulvar relapse. Moreover, almost all cases of inguinal relapse occurred within 2 years after the end of treatment (fig. 4). Similar observations were presented by Cormio et al., who showed that the median survival after groin recurrence was 9 months and the median time from primary surgery to groin relapse was 7 months [30].

\section{Conclusions}

The conclusions of the study are:

- a tumor size $>25 \mathrm{~mm}$ and inguinal lymph node involvement are independent prognostic factors for survival in vulvar cancer patients,

- groin recurrence is associated with an unfavorable prognosis,

- vulvar cancer relapses may occur many years after treatment; at the time it is located on the vulva,

- an inadequate surgical margin would be salvaged by RT or RCT.

Conflict of interest: none declared

\section{Szymon Piątek}

Maria Sklodowska-Curie National Research Institute of Oncology Department of Gynecologic Oncology

ul. Roentgena 5

02-781 Warszawa, Poland

e-mail:szymon.piatek@aol.com 
Received: 15 May 2021

Accepted: 6 Jul 2021

\section{References}

1. NCCN Clinical Practice Guidelines in Oncology. Vulvar Cancer (Squamous Cell Carcinoma). Version 2.2019. https://www2.tri-kobe.org/nccn/ guideline/gynecological/english/vulvar.pdf.

2. Oonk MHM, Planchamp F, Baldwin P, et al. European Society of Gynaecological Oncology Guidelines for the Management of Patients With Vulvar Cancer. Int J Gynecol Cancer. 2017; 27(4): 832-837, doi: 10.1097/ IGC.0000000000000975, indexed in Pubmed: 28441255.

3. Pijnenborg JMA, Boll D, Hermans $\mathrm{RH}$, et al. Recurrence rate in vulvar carcinoma in relation to pathological margin distance. Int J Gynecol Cancer. 2010; 20(5): 869-873, doi: 10.1111/IGC.0b013e3181df7423, indexed in Pubmed: 20606536.

4. Baiocchi $\mathrm{G}$, Mantoan $\mathrm{H}$, de Brot $\mathrm{L}$, et al. How important is the pathological margin distance in vulvar cancer? Eur J Surg Oncol. 2015; 41(12): 1653-1658, doi: 10.1016/j.ejso.2015.09.024, indexed in Pubmed: 26507171.

5. Imoto S, Inamine M, Kudaka W, et al. Prognostic factors in patients with vulvar cancer treated with primary surgery: a single-center experience. Springerplus. 2016; 5: 125, doi: 10.1186/s40064-016-1767-7, indexed in Pubmed: 26933624.

6. Viswanathan AN, Pinto AP, Schultz D, et al. Relationship of margin status and radiation dose to recurrence in post-operative vulvar carcinoma. Gynecol Oncol. 2013; 130(3): 545-549, doi: 10.1016/j. ygyno.2013.05.036, indexed in Pubmed: 23747330.

7. Micheletti L, Preti M, Cintolesi V, et al. Prognostic impact of reduced tumor-free margin distance on long-term survival in FIGO stage IB/II vulvar squamous cell carcinoma. J Gynecol Oncol. 2018; 29(5): e61, doi: 10.3802/jgo.2018.29.e61, indexed in Pubmed: 30022627.

8. Woelber L, Mahner S, Voelker K, et al. Clinicopathological prognostic factors and patterns of recurrence in vulvar cancer. Anticancer Res. 2009; 29(2): 545-552, indexed in Pubmed: 19331201.

9. Raimond E, Delorme C, Ouldamer L, et al. Research group FRANCOGYN. Surgical treatment of vulvar cancer: Impact of tumor-free margin distance on recurrence and survival. A multicentre cohort analysis from the francogyn study group. Eur J Surg Oncol. 2019; 45(11): 2109-2114, doi: 10.1016/j.ejso.2019.07.005, indexed in Pubmed: 31285094.

10. Bedell SM, Hedberg C, Griffin A, et al. Role of adjuvant radiation or reexcision for early stage vulvar squamous cell carcinoma with positive or close surgical margins. Gynecol Oncol. 2019; 154(2): 276-279, doi: 10.1016/j.ygyno.2019.05.028, indexed in Pubmed: 31171409.

11. Arvas M, Kahramanoglu I, Bese T, et al. The Role of Pathological Margin Distance and Prognostic Factors After Primary Surgery in Squamous Cell Carcinoma of the Vulva. Int J Gynecol Cancer. 2018; 28(3): 623-631, doi: 10.1097/IGC.0000000000001195, indexed in Pubmed: 29324545.

12. Woelber $L$, Griebel LF, Eulenburg $C$, et al. Role of tumour-free margin distance for loco-regional control in vulvar cancer-a subset analysis of the Arbeitsgemeinschaft Gynäkologische Onkologie CaRE-1 multicenter study. Eur J Cancer. 2016; 69: 180-188, doi: 10.1016/j.ejca.2016.09.038, indexed in Pubmed: 27837710.

13. Schnürch HG, Ackermann S, Alt CD, et al. Diagnosis, Therapy and Followup Care of Vulvar Cancer and its Precursors. Guideline of the DGGG and DKG (S2k-Level, AWMF Registry Number 015/059, November 2015. Geburtshilfe Frauenheilkd. 2016; 76(10): 1035-1049, doi: 10.1055/s0042-103728, indexed in Pubmed: 27765958.

14. Nooij LS, van der Slot MA, Dekkers OM, et al. Tumour-free margins in vulvar squamous cell carcinoma: Does distance really matter? Eur J Cancer. 2016; 65: 139-149, doi: 10.1016/j.ejca.2016.07.006, indexed in Pubmed: 27497345.
15. Te Grootenhuis NC, Pouwer AFW, de Bock GH, et al. Prognostic factors for local recurrence of squamous cell carcinoma of the vulva: A systematic review. Gynecol Oncol. 2018; 148(3): 622-631, doi: 10.1016/j. ygyno.2017.11.006, indexed in Pubmed: 29137809.

16. Woelber $L$, Choschzick M, Eulenburg $C$, et al. Prognostic value of pathological resection margin distance in squamous cell cancer of the vulva. Ann Surg Oncol. 2011; 18(13): 3811-3818, doi: 10.1245/s10434011-1778-0, indexed in Pubmed: 21594705.

17. Minar L, Felsinger $M$, Cihalova $M$, et al. Vulvar cancer recurrence - an analysis of prognostic factors in tumour-free pathological margins patients group. Ginekol Pol. 2018; 89(8): 424-431, doi: 10.5603/ GP.a2018.0073, indexed in Pubmed: 30215461.

18. Hay CM, Lachance JA, Lucas FL, et al. Biomarkers p16, Human Papillomavirus and p53 Predict Recurrence and Survival in Early Stage Squamous Cell Carcinoma of the Vulva. J Low Genit Tract Dis. 2016; 20(3): 252-256, doi: 10.1097/LGT.0000000000000182, indexed in Pubmed: 26855143.

19. Ferrari F, Forte $S$, Ardighieri L, et al. Multivariate analysis of prognostic factors in primary squamous cell vulvar cancer: The role of perineural invasion in recurrence and survival. Eur J Surg Oncol. 2019; 45(11): 2115-2119, doi: 10.1016/j.ejso.2019.07.029, indexed in Pubmed: 31378417.

20. Wu SG, Zhang WW, Sun JY, et al. Prognostic Value of the Number of Removed Lymph Nodes in Vulvar Squamous Cell Carcinoma Patients With Node-Positive Disease: A Population-Based Study. Front Oncol. 2018; 8: 184, doi: 10.3389/fonc.2018.00184, indexed in Pubmed: 29900126.

21. Mahner S, Jueckstock J, Hilpert F, et al. AGO-CaRE 1 investigators. Adjuvant therapy in lymph node-positive vulvar cancer: the AGO-CaRE-1 study. J Natl Cancer Inst. 2015; 107(3), doi: 10.1093/jnci/dju426, indexed in Pubmed: 25618900.

22. Schwameis R, Postl M, Bekos C, et al. Prognostic value of serum creatine level in patients with vulvar cancer. Sci Rep. 2019; 9(1): 11129, doi: 10.1038/s41598-019-47560-3, indexed in Pubmed: 31366905.

23. Woelber L, Eulenburg C, Kosse J, et al. AGO-CaRE 1 investigators. Predicting the course of disease in recurrent vulvar cancer - A subset analysis of the AGO-CaRE-1 study. Gynecol Oncol. 2019; 154(3): 571-576, doi: 10.1016/j.ygyno.2019.07.009, indexed in Pubmed: 31324454.

24. Blecharz P, Karolewski K, Bieda T, et al. Prognostic factors in patients with carcinoma of the vulva--our own experience and literature review. Eur J Gynaecol Oncol. 2008; 29(3): 260-263, indexed in Pubmed: 18592791.

25. Nicoletto MO, Parenti A, Del Bianco $P$, et al. Vulvar cancer: prognostic factors. Anticancer Res. 2010; 30(6): 2311-2317, indexed in Pubmed: 20651385.

26. Polterauer S, Schwameis R, Grimm C, et al. VULCAN Study Collaborative Group. Prognostic value of lymph node ratio and number of positive inguinal nodes in patients with vulvar cancer. Gynecol Oncol. 2017; 147(1): 92-97, doi: 10.1016/j.ygyno.2017.07.142, indexed in Pubmed: 28797698.

27. Sznurkowski JJ, Milczek T, Emerich J. Prognostic factors and a value of 2009 FIGO staging system in vulvar cancer. Arch Gynecol Obstet. 2013; 287(6): 1211-1218, doi: 10.1007/s00404-012-2683-x, indexed in Pubmed: 23263173.

28. Holthoff ER, Jeffus SK, Gehlot A, et al. Perineural Invasion Is an Independent Pathologic Indicator of Recurrence in Vulvar Squamous Cell Carcinoma. Am J Surg Pathol. 2015; 39(8): 1070-1074, doi: 10.1097/ PAS.0000000000000422, indexed in Pubmed: 25786085.

29. Zapardiel I, lacoponi S, Coronado P, et al. Prognostic factors in patients with vulvar cancer: the VULCAN study. Int J Gynecol Cancer. 2020; 30(9): 1285-1291, doi: 10.1136/ijgc-2019-000526.

30. Cormio G, Loizzi V, Carriero C, et al. Groin recurrence in carcinoma of the vulva: management and outcome. Eur J Cancer Care (Engl). 2010; 19(3): 302-307, doi: 10.1111/j.1365-2354.2008.01011.x, indexed in Pubmed: 19832900. 